https://doi.org/10.48009/1_iis_2009_115-125

\title{
USING SAP ERP AND ORACLE DBMS TOOLS TO DEMONSTRATE AUTHORIZATION CONCEPTS
}

\author{
Deb Sledgianowski, Zarb School of Business, Hofstra University, deb.sledgianowski@ hofstra.du \\ Michael Devlin, Hofstra University, michael.p.devlin@hofstra.edu
}

\begin{abstract}
This paper discusses our development and use of course material to demonstrate database management systems concepts to students by using enterprise resource planning (ERP) system software to augment their learning. The purpose of our paper is to share our experience with other universities interested in using ERP software as a tool to supplement students' learning of information technology (IT) concepts as they may apply to an organizational setting. This paper describes the course material and tutorial we developed to facilitate students' understanding using a hands-on approach. We used Oracle as our relational database management system (DBMS) and SAP R/3 as our $E R P$ system. Students first learn the structure of $S Q L$ syntax and the specific commands that would enable them to create users and roles, and grant permissions. They then practice the SQL syntax that they learned by executing the commands in an actual $D B M S$. Then the students learn how to create user accounts and grant transaction authorization by using the tools provided by the Oracle DBMS system. And finally the students learn how to create user accounts and grant transaction authorization by using the tools provided by the ERP system. These same concepts can be applied to other relational DBMS such as Microsoft SQL Server and other ERP systems. Experiential learning theory provides the guiding framework for our approach.
\end{abstract}

Keywords: Integration, ERP, DBMS, SQL, SAP University Alliance, Action learning, Curricula

\section{INTRODUCTION}

Business school accreditation standards [1] call for participating schools to continuously improve instructional programs. Information systems curricula models suggest that students should have an understanding of IT from an organizational perspective and that students should have both applied and conceptual learning experiences $[6,2$, 11]. Enterprise resource planning information systems vendors, such as SAP and Oracle, having saturated the market for large-sized enterprises, have expanded into the mid-sized business market. The desire for continuous improvement of our curriculum, along with recent job market growth statistics projecting that the demand for database administrators is expected to increase up to $37 \%$ by 2016 [20], has encouraged us to integrate hands-on database administration exercises using ERP software into our IT DBMS courses. To facilitate student learning, we have developed a hands-on learning tutorial using ERP software to demonstrate DBMS administration concepts as they are applied to SAP $\mathrm{R} / 3$, a popular ERP system. Computer-based tutorials have been found to be a useful tool to facilitate learning of IT concepts [16].

\section{WHY USE ERP IN A BUSINESS SCHOOL CURRICULUM?}

ERP software has been widely adopted by large companies and is increasingly being adopted by small to medium sized companies. The business community has recognized the importance of ERP systems and made enormous investments into this new information technology [15]. Today there is no question that ERP systems are the backbone of the IT infrastructure of most large organizations [7].

The demand for trained enterprise resource planning professionals has motivated a number of universities to join alliances with ERP software vendors such as SAP [4]. Our institution is one of them. An educational objective to achieve the mission of our business school is to impart an understanding of information systems and other technologies and their use in both domestic and global environments.

It is very likely that business students majoring in Information Technology will be involved with ERP software in their careers as IT professionals or managers. Business majors in Accounting are likely to focus on internal controls, while Management Information Systems majors are more likely to focus on security [19]. It should also be noted that recent research indicates that university business school graduates who undertook ERP-intensive coursework received significantly higher salary offers than graduates who were not enrolled in ERP-intensive classes [7].

IT educators are sometimes reluctant to adopt new IT products, but need to weigh the costs and benefits of adopting technology innovations in their curriculum [8]. 
There are skeptics that argue that computer-based instruction is not superior to traditional teaching methods [5]. But in most IT courses, a software product must be used to teach the subject matter. Cisco products are often used in networking courses. Java is used in programming courses. Microsoft Windows and Linux are used in operating systems courses. Microsoft .NET products are used in web development courses. Microsoft SQL Server and Oracle DBMS are used in database management courses. These are examples of industry-leading products being used in university curricula. SAP is the leading supplier of ERP software and is the world's fourth largest software vendor [19]. Therefore, it makes sense that SAP R/3 can and should be used in courses addressing ERP topics, and in our case, a course in database management concepts.

Another view is such that the academic university setting should remain a bastion where concepts and theory are taught and that skills training should be relegated to vocational schools or the job site [7]. According to this view, training students in the use of a particular vendor product should not be a part of university coursework. As stated previously, this is not a particularly valid argument. The converse of this argument is that overemphasizing theoretical knowledge, neglecting problem solving and communication skills, and failing to provide students with an integrated realistic view of the business world are some of the most serious weaknesses identified in reports regarding the state of business school curriculum [17]. Many proponents would say that the integration of all of the business school curricula using an ERP system would greatly enhance the student experience.

Aside from those debates, however, the sheer complexity of ERP systems and a lack of "start-up" curricula have made it difficult to entice universities involvement at a high level [7]. This is a valid concern which is being addressed by SAP and its University Alliance. As a business school, it is our goal to provide students with the skills and knowledge that they will need to manage in today's global business environment. Historically speaking businesses have transformed immensely in the past 50 years as business practices utilized and integrated information systems within their business [11]. Traditionally, business school curricula reflect a vertical orientation of material within the typical disciplines of Management, Accounting, Economics, Human Resources, Marketing, Production Operations, and Management Information Systems
[11]. While such divisions have historically provided for logical organizational management of the business colleges, it has fostered an environment which does not adequately prepare graduates with the interdisciplinary depth required by today's demanding "enterprise" culture [11].

The SAP University Alliance supports our goals by providing the use of their SAP R/3 Business Suite software for a nominal fee to member schools. This software application can be used to demonstrate how IT is critical to the efficient performance of business processes that lead to increased productivity and corporate growth. A goal for our students is for them to gain hands-on experience of tasks similar to what they may experience in the real world to supplement IT concepts discussed in class. Additionally, SAP offers a certificate of recognition for students who successfully complete three courses that have a minimum of $30 \%$ SAP content. Educators should encourage their students to become certified in areas of their interest to achieve an advantage over noncertified graduates in the job market [12].

Nearly $70 \%$ of schools in the SAP University Alliance were classified as either "initial", with a silo approach to ERP education, or "adaptive", where the school largely uses exercises and curriculum developed at other institutions [3]. Only $7 \%$ of the institutions were developing new curriculum that could be used by the other schools in the Alliance [3]. Our university is currently in the process of moving from the "initial" or adaptive classification to being an institution that is developing new curriculum. The following is a description of the course material we developed for the SAP University Alliance along with a discussion of its grounding in active learning theory.

\section{IMPLEMENTING ACTIVE LEARNING}

We used an active learning method to facilitate learning in our undergraduate and graduate DBMS courses. A motivation for this course development was the model curricula for undergraduate information systems IS education [6, 9] which recommends providing a mix of experiential learning and theory in courses. Additionally, business school accreditation standards [1] encourage participating schools to continuously improve instructional programs and to use interdisciplinary approaches. The particular courses for which this material was developed are offered by the information technology department within a business school, so guiding the instructional delivery decisions were the goals to integrate information technology concepts with 
business concepts as well as to provide students with the opportunity to apply hands-on technical concepts.

Active learning and experiential learning are terms used to describe educational techniques where students learn by doing. These learning concepts, in part, are founded by the writings of John Dewey and Kurt Lewin. Influenced by Dewey and Lewin is the work of Kolb and Fry [13], who proposed the experiential learning circle, based on a four stage model (see Figure 1):

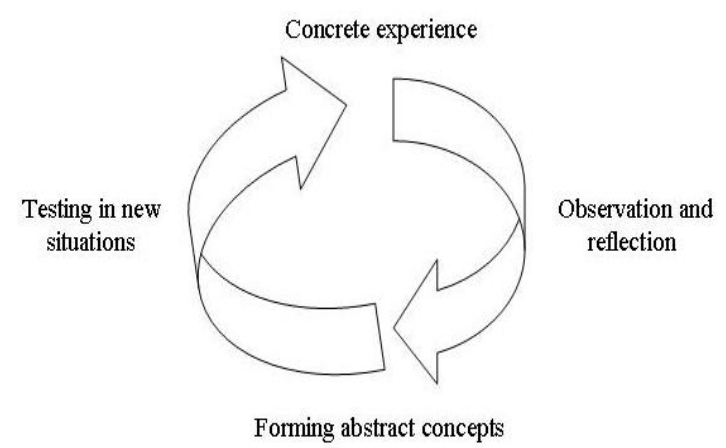

Figure 1. Experiential Learning Circle (adapted from [18])

Much pedagogic discourse has been generated around this model of experiential learning relative to the theory and practice of adult education [18]. Research using active and experiential learning techniques suggests that students may benefit by having hands-on experiences as part of their education process $[13,14]$.

Our DBMS course offerings at Hofstra University cover the development of a database application from conceptual modeling through logical design to implementation using desktop and enterprise DBMSs such as Microsoft Access and Oracle. Students learn SQL syntax to insert, update, delete, and query data in both of these relational DBMS.

A critical task of IT professionals responsible for database administration in organizations is to provide users of database applications with access to the data and to ensure the integrity and security of that data. This is commonly done by creating user accounts and granting access rights and privileges to those accounts. To broaden our students' experience, we decided to show them how these concepts are applied to an ERP system, similar to what they may experience in the real world during the span of their IT careers. We designed our tutorial to demonstrate using SAP R/3 as an enterprise software application to provide database access security. This tutorial demonstrates implementing data security by creating user accounts and granting them transaction

Volume X, No. 1, 2009 authorization. The tutorial, relative to Kolb and Fry's experiential learning circle model, is discussed below:

In the data security tutorial, students first learn the structure of SQL syntax and the specific commands that would enable them to create users and roles and grant permissions. We consider this to be a manifestation of the "experience" stage of Kolb and Fry's learning cycle.

Next the students practice the SQL syntax that they just learned by executing the commands in an actual DBMS (see Table 1). They learn to understand the effects of the SQL commands in a particular instance so that if the same actions were taken in similar circumstances it would be possible for them to anticipate what would follow from their action. We consider this to be a manifestation of the "observation and reflection" stage.

Table 1. SQL Syntax to Create User, Role, and Grant Permissions

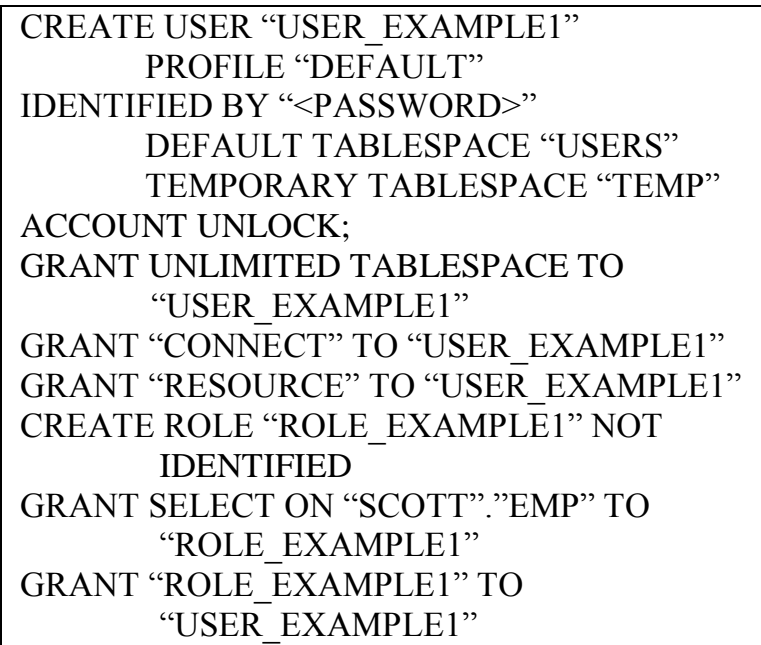

Then the students learn how to create user accounts and grant transaction authorization by using the tools provided by the Oracle DBMS system (see Figure 2 through Figure 6), the "formation of abstract concepts" stage. In our case, since we are using Oracle as the relational DBMS, our examples use Oracle's Enterprise Manager (OEM) tool. It is anticipated that the students come to the abstract realization that this new method used to create the user accounts and grant permissions in the OEM tool, in effect caused the same SQL commands they had just learned to be executed "behind the scenes" by the database engine. They can see this by clicking on the "Show SQL" button. 
Then the students learn how to create user accounts and grant transaction authorization by using the tools provided by the ERP system (see Figure 7 through Figure 16). This is considered the "testing in new situations" stage. It is anticipated that the students come to the abstract realization that the method that they used to create the user accounts and grant access in the ERP system in effect caused the same SQL commands they had just learned to be executed "behind the scenes" by the database engine, much the same way as demonstrated with the OEM tool.

The students can then apply the concepts they have learned to new situations, the "testing in new situations" stage. In our case, we have the students learn additional SQL syntax for other DBMS functionality, such as creating and modifying physical database structures (tables and views). The students then learn how to do this with the ERP system, realizing that there are also vendor-provided tools for these tasks and that ultimately these tools execute the same SQL commands that they just learned. We anticipate this realization would also occur when the students use other ERP or enterprise systems which are built on a relational DBMS backend.

\section{CONCLUSIONS}

DBMS courses typically teach database administration concepts such as database control using authorization rules and discretionary access, and understanding the role of the data dictionary. Students' learning of these concepts can be reinforced by allowing them to assimilate their learning to a real-world situation using ERP software. Preliminary feedback from our students has been positive, with most believing that this experience will better prepare them in applying the concepts they learned to real world systems.

Our experience with students using the tutorial has been positive, encouraging us to develop additional tutorials and learning aids. Future plans include developing learning objects of DBMS concepts and publishing them in podcasts available online and distributed via our course management system. Podcast materials can be viewed on-line or downloaded to be viewed off-line. This frees the student from time and location constraints. This enables learning concepts already discussed to be reviewed at the student's convenience, enabling classroom time to be used to learn new concepts rather than reviewing concepts previously covered. Further research is needed to examine the effects of using this new curriculum material on educational outcomes.

\section{ACKNOWLEDGEMENT}

This research was sponsored by a Summer Research Grant from the Frank G. Zarb School of Business at Hofstra University.

\section{REFERENCES}

1. AACSB (2008). Eligibility procedures and standards for business accreditation. Retrieved April 11, 2009 from http://www.aacsb.edu/accreditation/standards.asp 2. Al-Rawi, A., Lansari, A. and Bouslama, F. (2005). A holistic approach to develop IS curricula: Focusing on accreditation and IT certification. Journal of Information Technology Education, 4, 307-327. 3. Antonucci, Y., Corbitt, G., Stewart, G., and Haris, A. (2004). Enterprise systems education: Where are we? Where are we going?" Journal of Information Systems Education, 15(3), 227-234.

4. Becerra-Fernandez, I., Murphy, K. and Simon, S. (2004). Integrating ERP in the business school curriculum. Communications of the ACM, 41(4), 3941.

5. Bloom, M., and Hanych, D. (2002). Skeptics and true believers hash it out. Community College Week, 14(15), 17.

6. Cohen, E. (ed.) (2000). Curriculum model 2000 of the Information Resource Management Association and the Data Administration Managers Association. 7. Connolly, J., Corbitt, G., Mensching, J. and Sager, J. (2005). Benefits of academic alliance education: The employers perspective. Enterprise Resource Planning: Teaching and Research Innovative Monograph I, 129-138.

8. Gillard, S., Bailey, D., and Nolan, E. (2008). Ten reasons for IT educators to be early adopters of IT innovations. Journal of Information Technology

Education, 7, 21-33.

9. Gorgone, J., Davis, G., Valacich, J., Topi, H., Feinstein, D., \& Longenecker, H. (2002). IS 2002 model curriculum and guidelines for undergraduate degree programs in information systems. Association for Information System.

10. Gorgone, J., Gray, P., Stohr, E., Valacich, J., and Wigand, R. (2006). MSIS 2006: Model curriculum and guidelines for graduate degree programs in information systems. Communications of the Association for Information Systems, 17, 1-56. 11. Holsing, D., Shirazi, F., Wagner, B. (2005). Interdisciplinary studies within a business school paradigm: An implementation strategy for interdisciplinary curricula, enterprise resource planning. Teaching and Research Innovative Monograph I, 89-101. 
12. Hunsinger, D. S. and Smith, M. A. (2008). Factors that influence information systems undergraduates to pursue IT certification. Journal of Information Technology Education, 7, 255-273.

13. Kolb. D. A. and Fry, R. (1975).Toward an applied theory of experiential learning, in C. Cooper (ed.), Theories of Group Process, London: John Wiley, 33-57.

14. Marshall, K. and Pearson, M. (2007). A spreadsheet pricing model approach to teaching practical pricing concepts in the marketing classroom. Marketing Education Review, (17)1, 8793.

15. Matolcsy, Z., Booth, P., and Wieder, B. (2005). Economic benefits of enterprise resource planning systems: Some empirical evidence. Accounting and Finance, 45, 439-456.

16. Palvia, S. and Palvia, P. (2007). The effectiveness of using computers for software training: An exploratory study. Journal of Information Systems Education, 18(4), 479-489.

17. Porter, L. and McKibbin, L. (1988). Management education and development: Drift or thrust into the $21^{\text {st }}$ Century. New York: McGraw-Hill.

18. Smith, M. K. (2001). David A. Kolb on experiential learning. The Encyclopedia of Informal Education.__Retrieved April 11, 2009 from http://www.infed.org/biblio/b-explrn.htm

19. Tribunella, T. and Baroody, J. (2005). Investigating enterprise systems and SAP: A case study. Enterprise Resource Planning: Teaching and Research Innovative Monograph I, 103-127

20. U.S. Bureau of Labor Statistics. (2008). Occupational Outlook Quarterly. Retrieved April 11, 2009 from: http://www.bls.gov/oco/ocos042.htm

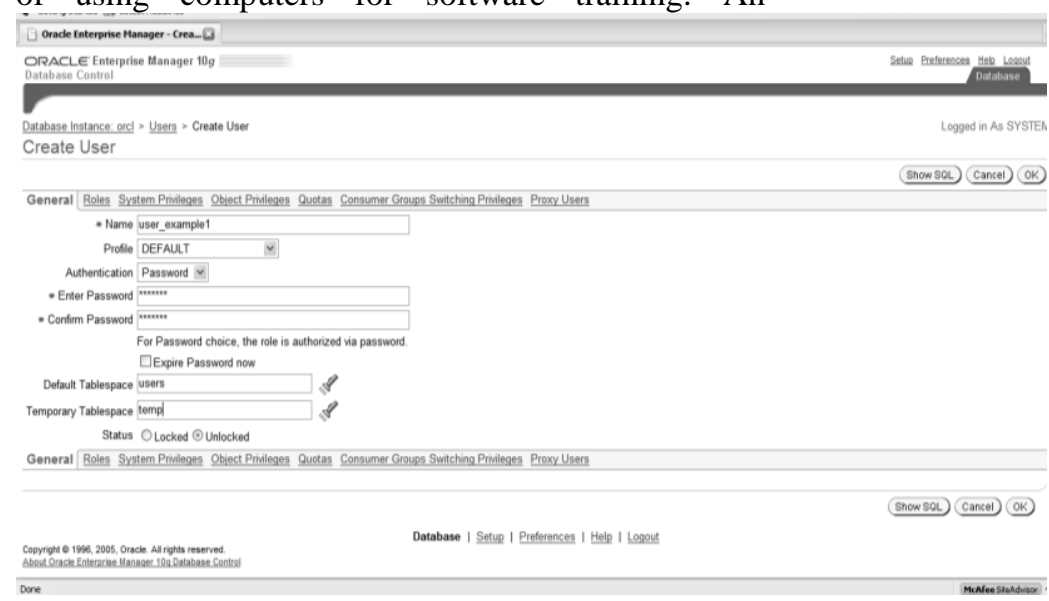

Figure 2. Using OEM to Create a User

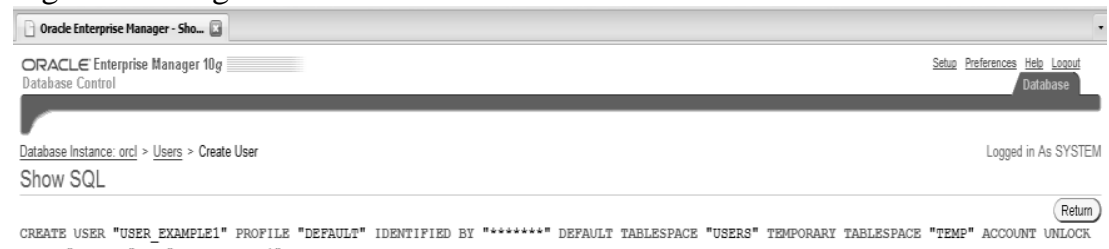

CRRATR USER "USER ENMPHEI" PROPI

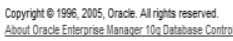

Database | Setup | Preferences | Help | Logout

Figure 3. SQL Syntax to Create User as Displayed in OEM 


\begin{tabular}{|c|c|}
\hline$\checkmark$ Oracle Enterprise Manager - Crea... $\otimes$ & - \\
\hline $\begin{array}{l}\text { ORACL } \in \text { Enterprise Manager } 10 \mathrm{~g} \\
\text { Database Control }\end{array}$ & Setup Preferences $\frac{\text { Help Logout }}{\text { Database }}$ \\
\hline Database Instance: orcl $>$ Roles $>$ Create Role & Logged in As SYSTEM \\
\hline \multicolumn{2}{|l|}{ Create Role } \\
\hline & Show SQL Cancel OK \\
\hline General Roles System Privileges Object Privileges $\underline{\text { Consumer Groups Switching Privileges }}$ & \\
\hline \multicolumn{2}{|l|}{ Name ROLE_EXAMPLE1 } \\
\hline \multirow{2}{*}{\multicolumn{2}{|c|}{ 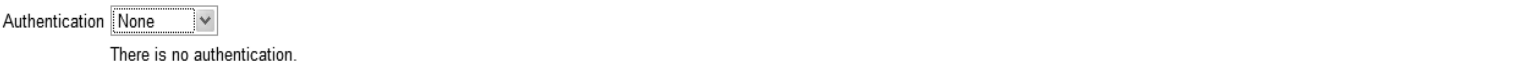 }} \\
\hline & \\
\hline \multicolumn{2}{|l|}{ General Roles System Privileges Object Privileges Consumer Groups Switching Privileges } \\
\hline & Show $5 Q \mathrm{~L}$ Cancel OK \\
\hline Database | Setup I Preferences I Help I Logout & \\
\hline
\end{tabular}

Figure 4. Using OEM to Create a Role

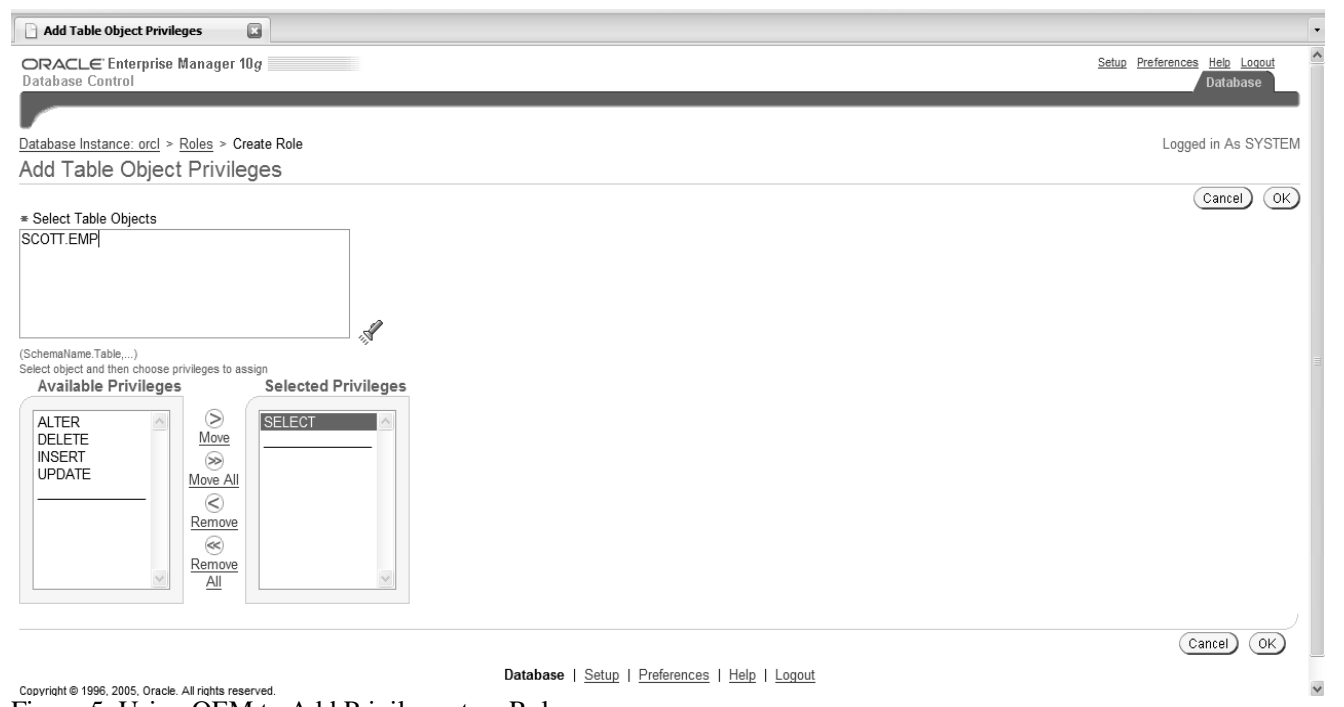

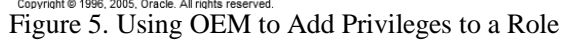

\begin{tabular}{l} 
D Oracle Enterprise Manager-Sho... $\otimes$ \\
ORACLE Enterprise Manager $10 \mathrm{~g}$ \\
Database Control \\
Database Instance: orcl > Roles > Create Role \\
ShOW SQL \\
CREATE ROLE "ROLE_EXAMPLE1" NOT IDENTIFIED \\
GRANT SELECT ON "SCOMT". "EMP" TO "ROLE_EXAMPLE1" \\
\hline
\end{tabular}

Copyright $\odot 1996,2005$, Oracle. All rights reserved.

Database | $\underline{\text { Setup } \mid \underline{\text { Preferences }} \text { | } \underline{\text { Help }} \text { | Logout }}$ About Oracle Enterprise Manager $10 a$ Database Control

Figure 6. SQL Syntax to Create Role as Displayed in OEM 


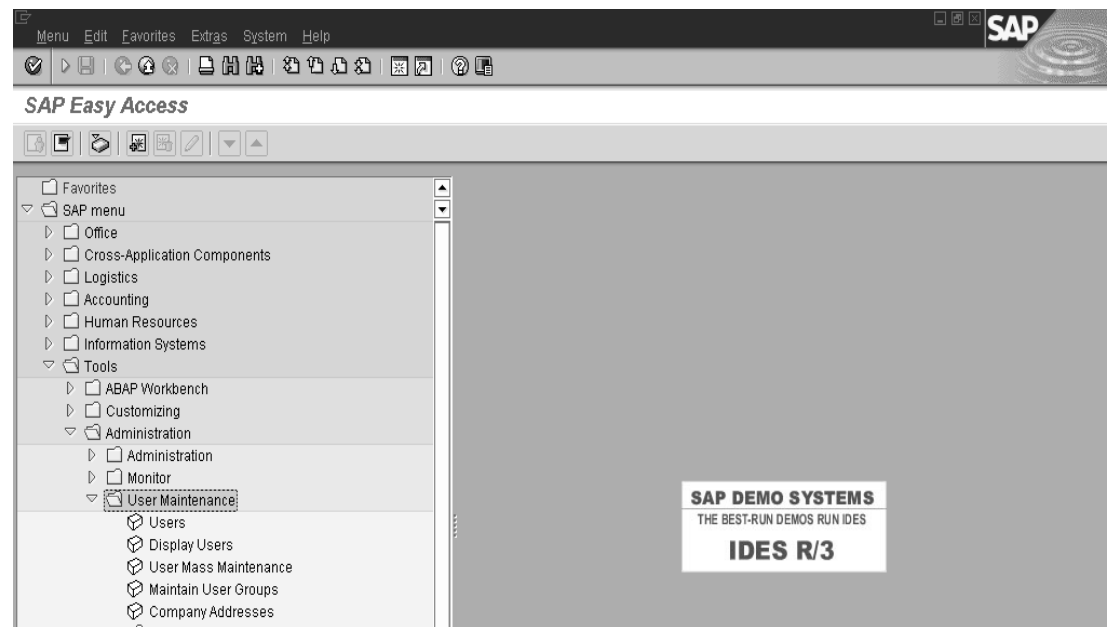

Figure 7. SAP R/3 Menu Path to User Maintenance

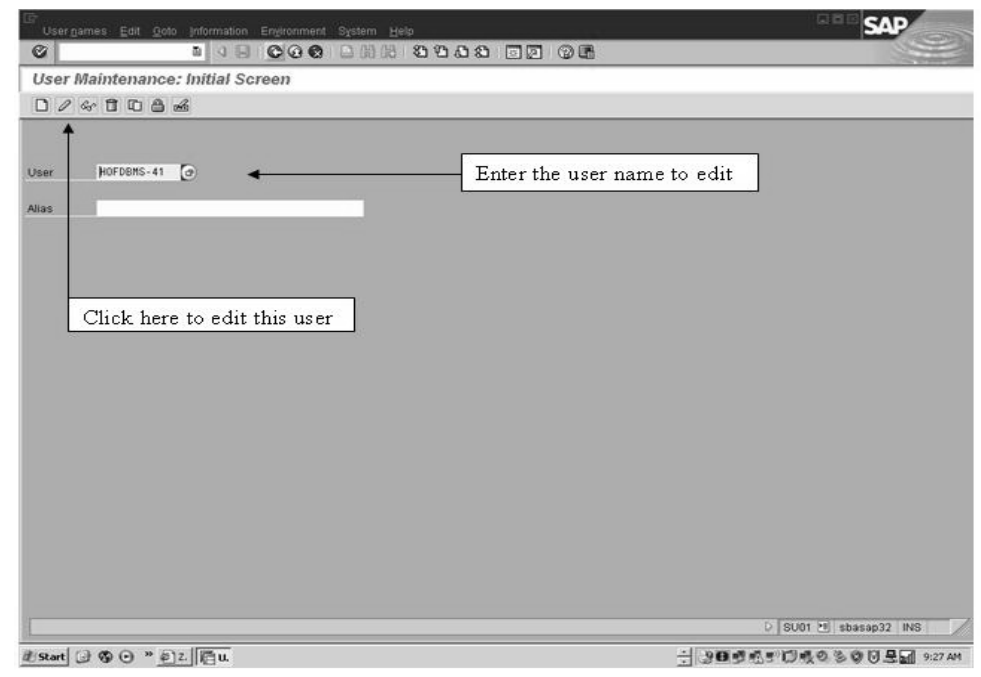

Figure 8. User Tries Transaction w/out Authorization

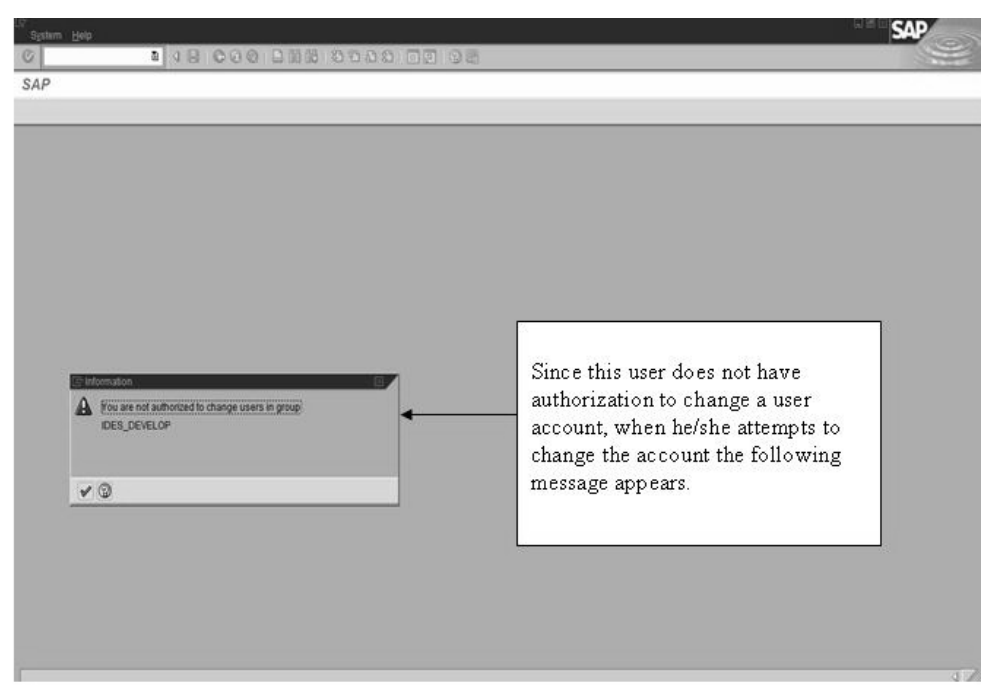

Figure 9. Error Message Generated by Unauthorized Access 


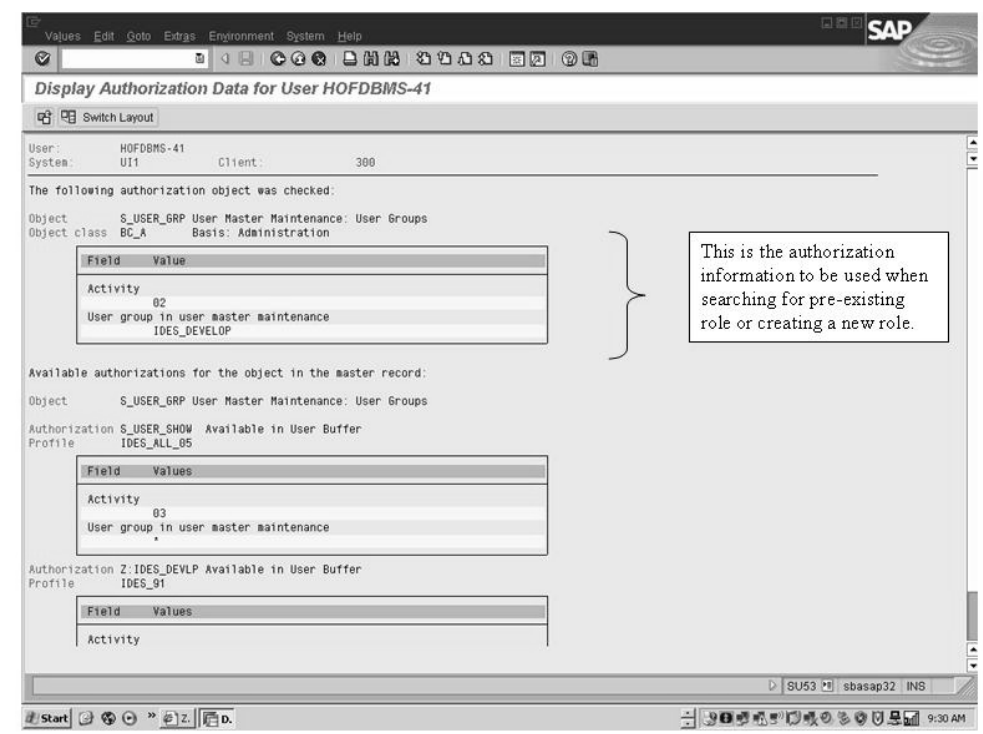

Figure 10, Display of User Authorization Needed

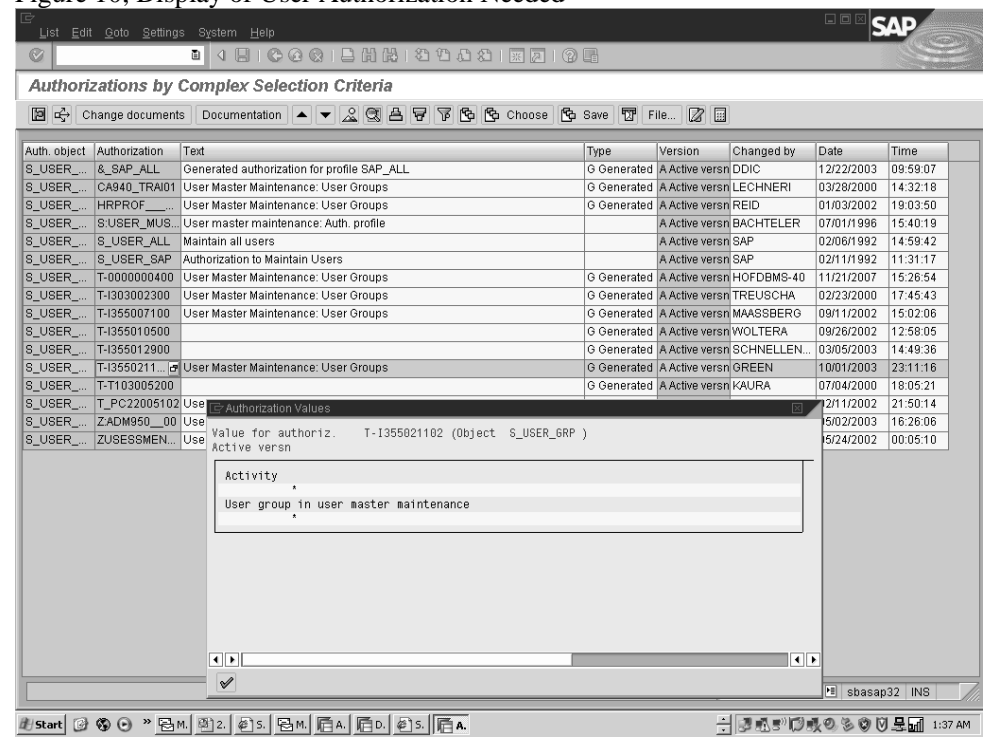

Figure 11, User Authorization Selection

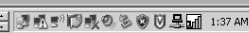




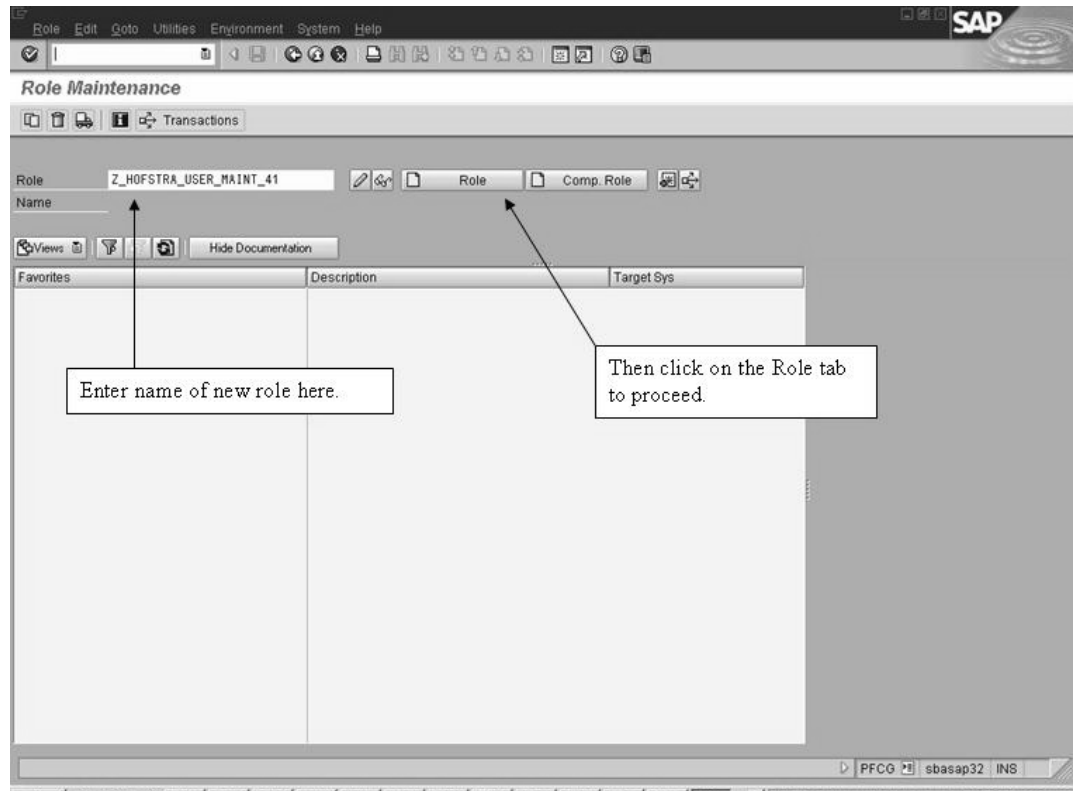

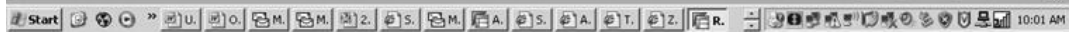
Figure 12. Role Maintenance Transaction

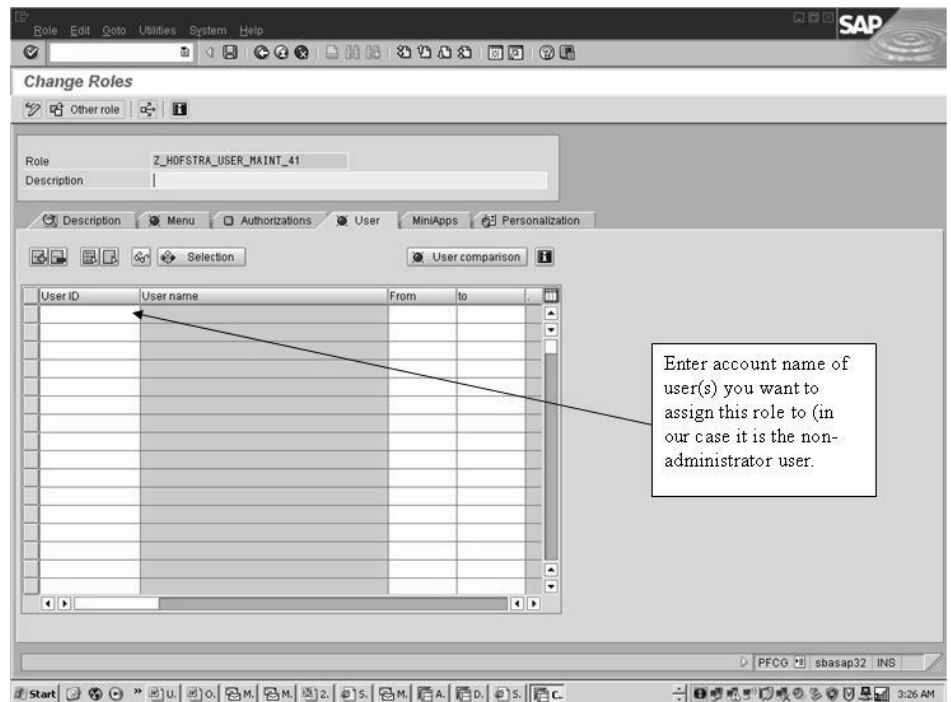

Figure 13. Add Role to User Accounts 


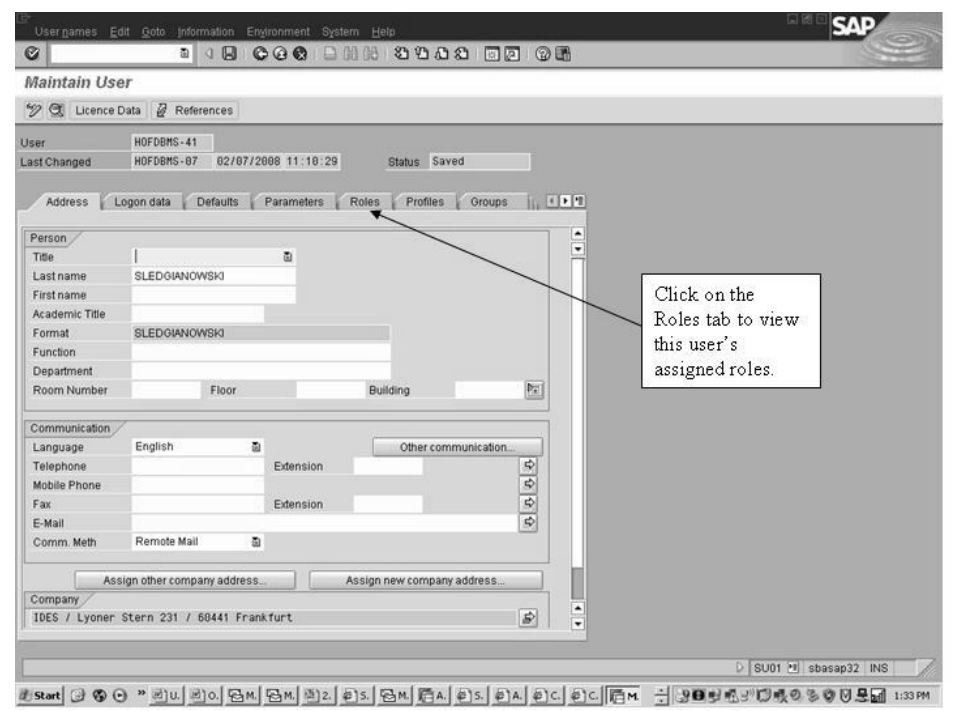

Figure 14. User Account Maintenance Transaction

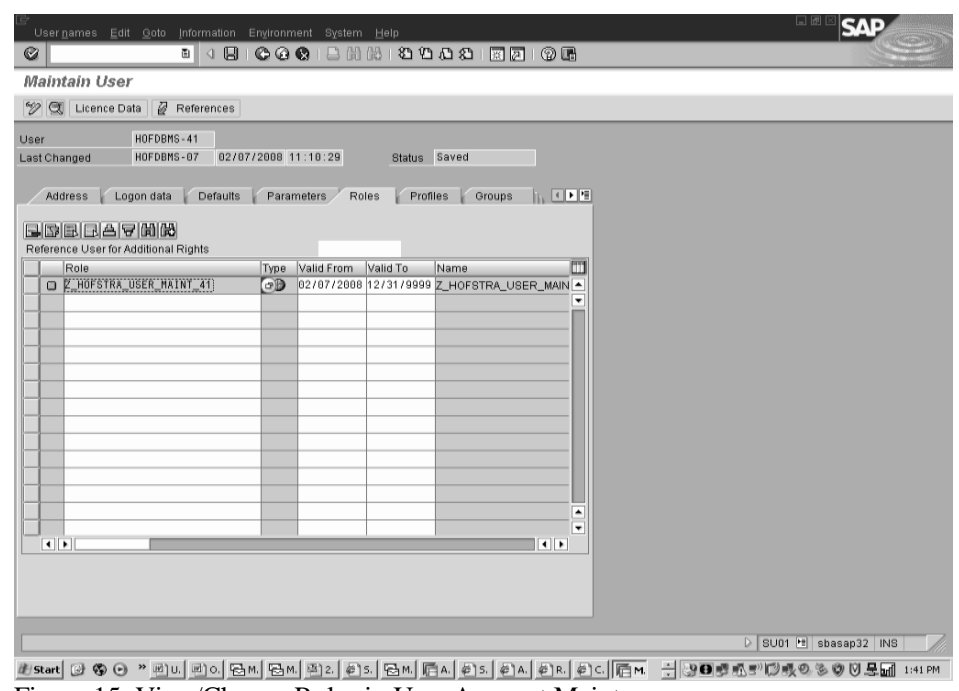

Figure 15. View/Change Roles in User Account Maintenance 
Figure 16: View, Change, and Add Profiles to User Account

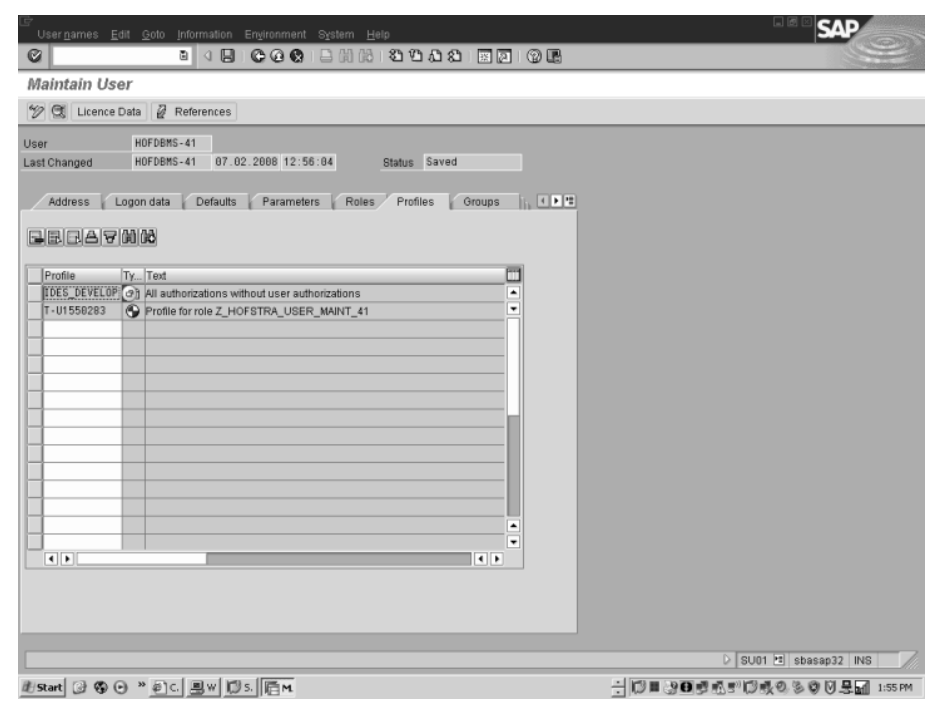

